ARTICLE

\title{
Entropy-stabilized single-atom Pd catalysts via high-entropy fluorite oxide supports
}

Haidi Xu (1) 1,2,3, Zihao Zhang ${ }^{2,3}$, Jixing Liu ${ }^{3}$, Chi-Linh Do-Thanh (1) ${ }^{3}$, Hao Chen ${ }^{3}$, Shuhao Xu', Qinjing Lin ${ }^{4}$, Yi Jiao ${ }^{1}$, Jianli Wang ${ }^{4}$, Yun Wang (10 ${ }^{5 凶}$, Yaoqiang Chen (10) ${ }^{1,4 凶} \&$ Sheng Dai ${ }^{2,3 凶}$

Single-atom catalysts (SACs) have attracted considerable attention in the catalysis community. However, fabricating intrinsically stable SACs on traditional supports (N-doped carbon, metal oxides, etc.) remains a formidable challenge, especially under hightemperature conditions. Here, we report a novel entropy-driven strategy to stabilize $\mathrm{Pd}$ single-atom on the high-entropy fluorite oxides (CeZrHfTiLa) $\mathrm{O}_{x}(\mathrm{HEFO})$ as the support by a combination of mechanical milling with calcination at $900^{\circ} \mathrm{C}$. Characterization results reveal that single Pd atoms are incorporated into HEFO (Pd,@HEFO) sublattice by forming stable $\mathrm{Pd}-\mathrm{O}-\mathrm{M}$ bonds $(\mathrm{M}=\mathrm{Ce} / \mathrm{Zr} / \mathrm{La})$. Compared to the traditional support stabilized catalysts such as $\mathrm{Pd@CeO}, \mathrm{Pd}_{1} @ \mathrm{HEFO}$ affords the improved reducibility of lattice oxygen and the existence of stable $\mathrm{Pd}-\mathrm{O}-\mathrm{M}$ species, thus exhibiting not only higher low-temperature $\mathrm{CO}$ oxidation activity but also outstanding resistance to thermal and hydrothermal degradation. This work therefore exemplifies the superiority of high-entropy materials for the preparation of SACs.

\footnotetext{
${ }^{1}$ Institute of New Energy and Low-Carbon Technology, Sichuan University, Chengdu 610064, China. ${ }^{2}$ Chemical Sciences Division, Oak Ridge National Laboratory, Oak Ridge, TN 37831, USA. ${ }^{3}$ Department of Chemistry, Joint Institute for Advanced Materials, University of Tennessee, Knoxville, TN 37996, USA. ${ }^{4}$ College of Chemistry, Sichuan University, Chengdu 610064, China. ${ }^{5}$ Sinocat Environmental Technology Co. Ltd., Chengdu 611731, China.

凶email: wangy@sinocat.com.cn; nic7501@scu.edu.cn; dais@ornl.gov
} 
$\mathrm{H}$ igh-entropy alloys (HEAs) with five or more elemental species have been successfully synthesized and have attracted extensive attention due to their unique physical properties and potential applications ${ }^{1-3}$. Compared with HEAs, it is more difficult to yield the formation of high entropy ceramics including oxides, carbides, nitrides et al. owing to their larger heats of formation. Since 2015, the family of high entropy materials has been expanded when the first entropy-stabilized oxides (HEOs) were reported by Rost et al. ${ }^{4}$. HEOs, a kind of multicationic equiatomic oxides, were then found to have a variety of interesting and unexpected characteristics ${ }^{5}$. Inspired from this discovery, several kinds of high-entropy oxides with different crystal structures were then reported one after another, such as perovskite oxide ${ }^{6,7}$, spinel oxide ${ }^{8}$, and fluorite oxide ${ }^{9-11}$. Quite recently, new entropy-stabilized single-phase fluorite oxides (HEFO) $\mathrm{Hf}_{0.25} \mathrm{Zr}_{0.25} \mathrm{Ce}_{0.25} \mathrm{Y}_{0.25} \mathrm{O}_{2-\delta} 11$ and $\mathrm{Ce}_{0.2} \mathrm{Zr}_{0.2} \mathrm{Hf}_{0.2} \mathrm{Sn}_{0.2^{-}}$ $\mathrm{Ti}_{0.2} \mathrm{O}_{2}{ }^{12}$ were also synthesized by using high-energy ball milling. However, rigorous synthetic conditions, including the long reaction time $(6-24 \mathrm{~h})$, ultra-high temperature $\left(1500-1800^{\circ} \mathrm{C}\right)$, and uniaxial high pressure, limit its application in catalysis.

Fluorite oxide-supported noble metals including SACs are widely used as heterogeneous catalysts with superior catalytic performances for mitigating critical pollutants (e.g., $\mathrm{CO}, \mathrm{CH}_{4}$, $\mathrm{HCs}$, and $\mathrm{NO}_{\mathrm{x}}$ ) from engine emissions. A wide range of hosts (metal oxides, $\mathrm{N}$-doped $\mathrm{C}$, zeolites, MOFs, etc.) are known for their ability to stabilize single atoms ${ }^{13}$. Recent advances in synthetic strategies for SACs are generally dominated by wet-chemistry approaches including defect engineering, spatial confinement, and coordination design strategies ${ }^{14,15}$. Mechanochemistry scenarios, which have attracted more interest because of their quick, quantitative, and solvent-free properties compared with wet-chemistry approaches, however, have always been a great challenge for fabricating atomically dispersed metal sites ${ }^{16-18}$. In addition, the successful assembly of metal single atoms on conventional carriers often requires a very careful control of synthesis conditions, such as low temperature ${ }^{19,20}$, low metal loading ${ }^{21,22}$, grafting of $\mathrm{N}$-rich organic linkers ${ }^{23,24}$, etc. Therefore, fabricating sintering-resistant SACs with intrinsically thermodynamic stability on high-entropy supports by using a solvent-free synthetic strategy is highly desirable.

Herein, we present a mechanochemical-assisted synthesis of $\mathrm{Pd}$ single atoms substituted on HEFO by simple mechanical milling followed by the calcination of metal precursors. The unique trait of HEFO can be validated by the formation of isolated Pd atoms on $\mathrm{Pd}_{1} @ \mathrm{HEFO}$, as well as the presence of Pd agglomeration with $\mathrm{CeO}_{2}$ as an alternative carrier under the same preparation conditions. A series of characterizations including high-resolution transmission electron microscopy (HRTEM), energy-dispersive X-ray spectroscopy (EDS) mapping, extended X-ray absorption fine structure (EXAFS), and diffuse reflectance infrared Fourier transform spectroscopy (DRIFTS) measurements are employed to unravel the existence of high-entropy phase and isolated $\mathrm{Pd}$ atoms in $\mathrm{Pd}_{1} @ \mathrm{HEFO}$. The catalytic activity of $\mathrm{CO}$ oxidation, as well as the resistance to thermal and hydrothermal degradation are then compared for $\mathrm{Pd}_{1} @ \mathrm{HEFO}$ and $\mathrm{Pd} @ \mathrm{CeO}_{2}$ catalysts to prove the advantages of $\mathrm{HEFO}$ as the catalyst carrier.

\section{Results}

Synthesis and characterizations. As illustrated in Fig. 1, six metal salt precursors (Ce, $\mathrm{Zr}, \mathrm{Hf}, \mathrm{Ti}, \mathrm{La}$, and $\mathrm{Pd}$ ) are first mixed with fumed silica by ball milling. The resultant mixture is pyrolyzed at $900{ }^{\circ} \mathrm{C}$ in air to achieve the silica-templated metal oxide complex. Finally, $\mathrm{Pd}_{1} @ \mathrm{HEFO}$ catalyst is obtained after etching silica with $\mathrm{NaOH}$. It should be noted that the molar ratios of $\mathrm{Ce}, \mathrm{Zr}, \mathrm{Hf}, \mathrm{Ti}$, and La are approximately 1:1:1:1:1 confirmed by both EDS and inductively coupled plasma (ICP) results listed in Supplementary Table 1. The high surface-area HEFO is synthesized through the same steps without the addition of Pd precursor; $\mathrm{Pd} @ \mathrm{CeO}_{2}$ counterpart is prepared by the same method; the single-phase $\mathrm{CeO}_{2}, \mathrm{TiO}_{2}, \mathrm{ZrO}_{2}, \mathrm{La}_{2} \mathrm{O}_{3}$, and $\mathrm{HfO}_{2}$ are obtained from facile pyrolysis of their corresponding metal salts at $900{ }^{\circ} \mathrm{C}$.

Powder X-ray diffraction (PXRD) (Fig. 2a) is performed to demonstrate the crystalline structure of HEFO and its corresponding single metal oxides. The cubic $\mathrm{CeO}_{2} \quad\left(c-\mathrm{CeO}_{2}\right)$, monoclinic $\mathrm{ZrO}_{2}\left(m-\mathrm{ZrO}_{2}\right)$, monoclinic $\mathrm{HfO}_{2}\left(m-\mathrm{HfO}_{2}\right)$, tetragonal $\mathrm{TiO}_{2}\left(t-\mathrm{TiO}_{2}\right)$, and tetragonal $\mathrm{La}_{2} \mathrm{O}_{3}\left(t-\mathrm{La}_{2} \mathrm{O}_{3}\right)$ are observed for the single metal oxides, respectively. Interestingly, HEFO exhibits only five obvious broad peaks centered at 30.2, 34.8, 50.2, 60.1 , and $62.6^{\circ}$, corresponding to (111), (200), (220), (311), and (222) planes of a single cubic phase. The absence of diffraction peaks indexed to $m-\mathrm{ZrO}_{2}, m-\mathrm{HfO}_{2}, t-\mathrm{TiO}_{2}$, and $t-\mathrm{La}_{2} \mathrm{O}_{3}$ indicates that $\mathrm{Zr}, \mathrm{Hf}, \mathrm{Ti}$, and $\mathrm{La}$ are all incorporated into $c-\mathrm{CeO}_{2}$ to form a new high-entropy (CeZrHfTiLa) $\mathrm{O}_{\mathrm{x}}$ solid solution (HEFO). Moreover, $\mathrm{Zr}^{4+}, \mathrm{Hf}^{4+}$, and $\mathrm{Ti}^{4+}$ except for $\mathrm{La}^{3+}$ have a smaller ion radius than $\mathrm{Ce}^{4+}$, thus resulting in an obvious shift of diffraction peaks of HEFO to a higher $2 \theta$ value compared with $c$ $\mathrm{CeO}_{2}$. The structural and chemical uniformity of HEFO is further evidenced by high-resolution TEM (HRTEM) and fast Fourier transfer (FFT, Fig. 2j) images, which show well-defined lattice fringes without the secondary phases. In addition, EDS-mapping results show the highly homogeneous dispersion of randomlydistributed five metal signals including $\mathrm{Ce}, \mathrm{Zr}, \mathrm{Hf}, \mathrm{Ti}$, and $\mathrm{La}$ (Fig. 2c-i), which also unambiguously suggests the formation of the high-entropy cubic phase of HEFO on nanometer scale. $\mathrm{N}_{2}$ adsorption-desorption isotherm and corresponding pore size distribution (Supplementary Figs. 1 and 2) of HEFO exhibit the emergency of rich porosity due to removal of hard-template $\mathrm{SiO}_{2}$ with a high specific surface area of $162.1 \mathrm{~m}^{2} \mathrm{~g}^{-1}$ (Supplementary Table 2). This porous structure of HEFO makes it a suitable candidate to be a catalyst carrier. The surface components of HEFO is mainly dominated by $\mathrm{Zr}^{4+}, \mathrm{Hf}^{4+}, \mathrm{Ti}^{4+}, \mathrm{Ce}^{4+}$, and $\mathrm{La}^{3+}$ shown by X-ray photoelectron spectroscopy (XPS, Supplementary Fig. 3) analysis, which indicates partial removal of oxygen in (CeZrHfTiLa) $\mathrm{O}_{\mathrm{x}} \quad(x<2)$ crystal after incorporation of $\mathrm{La}$ compared with $c-\mathrm{CeO}_{2}$. The schematic model of cubic HEFO is then constructed (Fig. $2 \mathrm{k}$ ) based on the above results, where the $\mathrm{Ce}$ atoms in $c-\mathrm{CeO}_{2}$ is randomly populated by $\mathrm{Zr}, \mathrm{Hf}, \mathrm{Ti}$, and $\mathrm{La}$ atoms.

After introducing 0.5-2 wt\% Pd during the synthesis of HEFO, the HEFO crystalline phase is well retained without the appearance of any additional diffraction peaks in Fig. 2b. More importantly, the absence of diffraction peaks ascribed to $\mathrm{Pd}$ species and the shift of diffraction peaks with the increases of $\mathrm{Pd}$ loading (Fig. 2b) suggests that a large portion of $\mathrm{Pd}$ may be incorporated into the HEFO sublattice for the formation of $\left(\mathrm{Pd}_{\mathrm{y}} \mathrm{CeZrHfTiLa}\right) \mathrm{O}_{\mathrm{x}}$ solid solution. After the introduction of $\mathrm{Pd}$ with different weight loading, the surface area and pore volume of $\mathrm{Pd}_{1} @ H E F O-x$ slightly decrease compared with pristine HEFO carrier (Supplementary Table 2). Fortunately, the surface area, pore size distribution and crystalline structure of $\mathrm{Pd}_{1} @ H E F O$ stay almost unchanged after both thermal and hydrothermal treatment (Supplementary Figs. 1, 2, and 4). The EDS-mapping results of $\mathrm{Pd}_{1} @ \mathrm{HEFO}$ in Fig. 3a-h suggest the uniform element distribution of $\mathrm{Pd}, \mathrm{Ce}, \mathrm{Zr}, \mathrm{Hf}, \mathrm{Ti}$, and La. More importantly, the agglomeration and sintering of Pd species are not observed in $\mathrm{Pd}_{1} @$ HEFO (Fig. 3b), indicating the possible existence of isolated $\mathrm{Pd}$ sites. The HRTEM image in Fig. 3i only depicts randomly oriented lattice spacing belonging to the HEFO phase. Consistent with EDS-mapping and HRTEM results, FFT pattern in Fig. 3i (inset) again reveals the diffraction rings from (111), (200), (220), (311), and (222), attributed to the face-centered cubic 
a
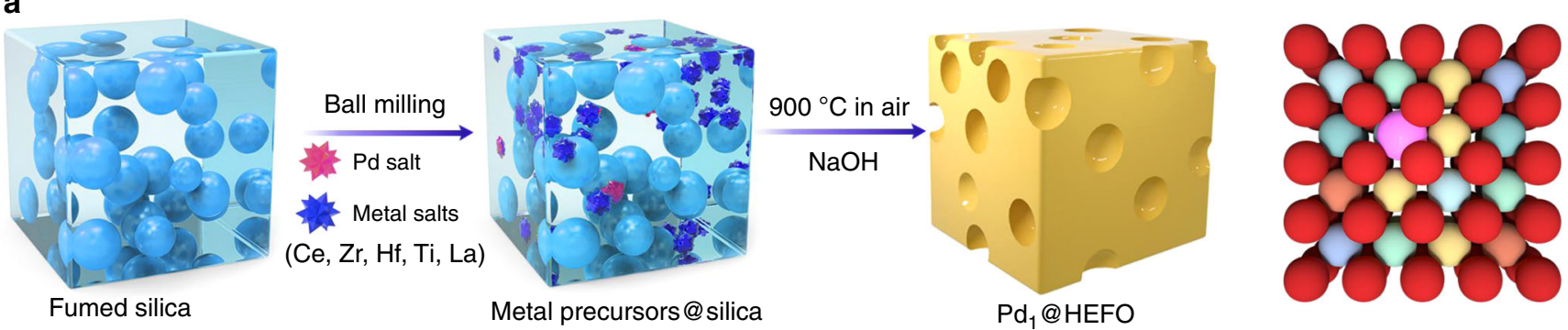

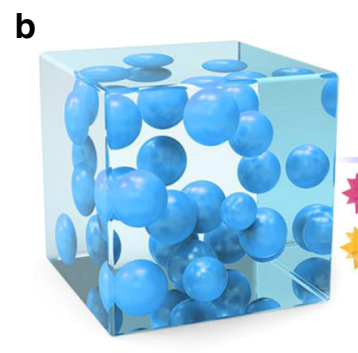

Fumed silica

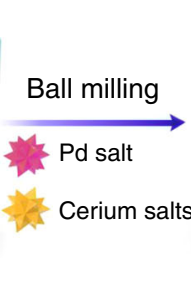

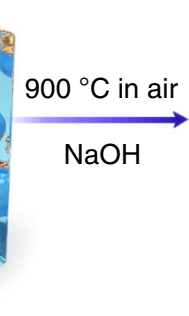

$\mathrm{Hf}$

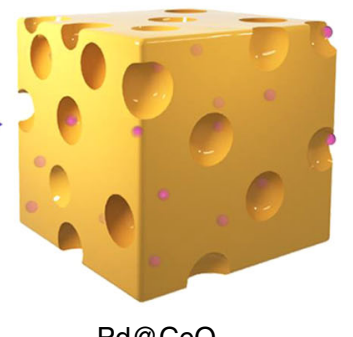

$\mathrm{Pd} @ \mathrm{CeO}_{2}$

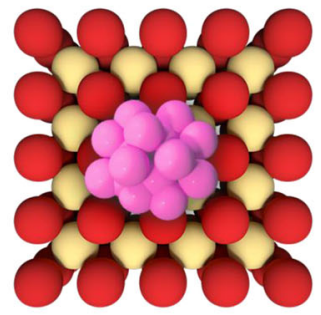

Ti

Fig. 1 Schematic illustration of mechanochemical-assisted route for the synthesis of serial catalysts. a $\mathrm{Pd}_{1} @ \mathrm{HEFO}$, showing the possible high dispersion of a small portion of Pd single atoms on the surface of HEFO support and incorporation of a large portion of Pd single atoms into HEFO sublattice after calcination at $900{ }^{\circ} \mathrm{C}$. b Pd@ $\mathrm{CeO}_{2}$, showing the aggregation of $\mathrm{Pd}$ clusters predominantly located on the surface of $\mathrm{CeO}$.

(CeZrHfTiLa) $\mathrm{O}_{\mathrm{x}}$ solid solution structure without diffraction rings ascribed to any $\mathrm{Pd}$ species. The above results confirm the existence of isolated Pd atoms, but the microenvironment of Pd still requires further exploration. In addition, TEM images of HEFO and $\mathrm{Pd}_{1} @ H E F O$ (Supplementary Fig. 5) display similar morphologies and the grains size distributions for both are centered at around $4 \mathrm{~nm}$. This suggests that the morphology and particle size of HEFO will not change after the introduction of Pd. Furthermore, the chemical state of $\mathrm{Pd}$ in $\mathrm{Pd}_{1} @ \mathrm{HEFO}$ is then investigated by XPS analysis, and the obtained binding energy (Supplementary Fig. 6) is the characteristic of electron-deficient $\mathrm{Pd}^{4+25-27}$. This formation of electron-deficient $\mathrm{Pd}^{4+}$ may be attributed to the electron transfer from $\mathrm{Pd}$ to $\mathrm{M}$ through $\mathrm{Pd}-\mathrm{O}-\mathrm{M}$ bonds $(\mathrm{M}=\mathrm{Ce}, \mathrm{Zr}, \mathrm{Hf}, \mathrm{Ti}$, and $\mathrm{La})$ in $\left(\mathrm{Pd}_{\mathrm{y}} \mathrm{CeZrHf}-\right.$ TiLa) $\mathrm{O}_{\mathrm{x}}$ solid solution.

The formation of single $\mathrm{Pd}$ atoms is further confirmed by atomic-resolution TEM image (Fig. 4a) and the corresponding Pd EDS-mapping image (Fig. 4b). The absence of $\mathrm{Pd}$ atoms outside HEFO lattice (Fig. 4a) and around $6.44 \%$ surface $\mathrm{Pd}$ atoms determined by $\mathrm{CO}$ chemisorption $(0.0644 \mu \mathrm{mol} \mathrm{CO} / \mu \mathrm{mol} \mathrm{Pd}$, Supplementary Table 1) together indicate that the $\mathrm{Pd}$ atoms have been incorporated into both surface and bulk HEFO phase in $\mathrm{Pd}_{1} @ H E F O$, consistent with the reported phenomena that single platinum-group metal atoms prefer to substitute cerium atoms of $\mathrm{CeO}_{2}$ rather than adsorb on its surface ${ }^{28}$. To confirm the electronic structure and coordination state of Pd in $\mathrm{Pd}_{1} @ \mathrm{HEFO}$, the X-ray absorption near-edge structure (XANES) and EXAFS measurements are performed at the Pd K-edge. XANES spectra show that the Pd K-edge absorption edge for $\mathrm{Pd}_{1} @ H E F O$ located between that of Pd foil and PdO (Fig. 4d), revealing the valence state of Pd is between 0 and +2 , which is lower than +4 of the surface Pd from XPS. This is probably attributed to the fact that the surface Pd atoms are more likely to be contacted with oxygen and be oxidized at high temperatures. Fourier-transformed $k^{3}$-weighted EXAFS spectra (Fig. 4e and Supplementary Table 3) exhibit the obvious Pd-Pd (bond length $=2.74 \AA$ ) and $\mathrm{Pd}-\mathrm{O}-\mathrm{Pd}$ (bond lengths $=3.06$ and $3.44 \AA$ ) features for $\mathrm{Pd}$ foil and $\mathrm{PdO}$ references, respectively, which are both absent in $\mathrm{Pd}_{1} @ H E F O$. As an alternative, the bond lengths at 3.01 and $3.26 \AA$ corresponding to $\mathrm{Pd}-\mathrm{O}-\mathrm{Zr}$ and $\mathrm{Pd}-\mathrm{O}-\mathrm{M}(\mathrm{M}=\mathrm{Ce} / \mathrm{La})$ are identified in $\mathrm{Pd}_{1} @ \mathrm{HEFO}$ (Supplementary Table 3), illustrating the existence of isolated $\mathrm{Pd}^{\mathrm{X}+}(0<x<2)$ in proximity to $\mathrm{Zr}$, Ce, or $\mathrm{La}$ atoms ${ }^{29-31}$. The wavelet transform plot (Fig. 4f) of $\mathrm{Pd}_{1} @ H E F O$ shows the wavelet transform maximum at $\sim 10 \AA^{-1}$, which corresponds to the $\mathrm{Pd}-\mathrm{O}-\mathrm{Zr}$ and $\mathrm{Pd}-\mathrm{O}-\mathrm{M}(\mathrm{M}=\mathrm{Ce} / \mathrm{La})$ bonding by comparing $\mathrm{Pd}$ foil and $\mathrm{PdO}$ counterparts and the intensity maxima of Pd-O-Ti at ca. $7 \AA^{-1}$ and $\mathrm{Pd}-\mathrm{O}-\mathrm{Hf}$ at above $12 \AA^{-1} 32,33$. Moreover, no intensity maxima corresponding to $\mathrm{Pd}-\mathrm{Pd}$ and $\mathrm{Pd}-\mathrm{O}-\mathrm{Pd}$ is found, which matches well with the EXAFS fitting results in $\mathrm{R}$ space. Consequently, a possible schematic model of $\mathrm{Pd}_{1} @ H E F O$ (220) is shown in Fig. 4c.

Operando diffuse reflectance infrared Fourier transform spectroscopy (DRIFTS) upon CO adsorption in Fig. 5a is then employed to examine the coordination environment of $\mathrm{Pd}$ in $\mathrm{Pd}_{1} @ \mathrm{HEFO}$ and $\mathrm{Pd} @ \mathrm{CeO}_{2}$. To strengthen the $\mathrm{CO}$ adsorption on $\mathrm{Pd}$ sites, $\mathrm{HEFO}, \mathrm{Pd}_{1} @ \mathrm{HEFO}$, and $\mathrm{Pd} @ \mathrm{CeO}_{2}$ are reduced in situ at $250^{\circ} \mathrm{C}$ in the DRIFTS cell before exposure to $\mathrm{CO}$ flow. For HEFO, the absence of FTIR bands in Fig. 4a suggests the surface of HEFO is not capable of adsorbing CO molecules. In comparison, $\mathrm{CO}$ frequencies between 2200 and $2000 \mathrm{~cm}^{-1}$ are clearly seen in $\mathrm{Pd}_{1} @ \mathrm{HEFO}$, which is assignable to CO molecules linearly adsorbed on single-atom $\mathrm{Pd}$ species $^{34,35}$. The bridge and hollow-CO bands are not seen in $\mathrm{Pd}_{1} @ \mathrm{HEFO}$, indicating that $\mathrm{Pd}$ are atomically dispersed on the HEFO host, which agrees with HAADF-STEM and EXAFS results ${ }^{34,36}$. However, the bridge and hollow-CO peaks are obviously observed for $\mathrm{Pd@CeO}$ because of the aggregation of $\mathrm{Pd}$ species, thus further validating the importance of hosts for the formation of isolated Pd species ${ }^{37}$. The obvious agglomeration of $\mathrm{Pd}$ in $\mathrm{Pd} @ \mathrm{CeO}_{2}$ can be also evidenced by EDS-mapping results (Supplementary Fig. 7) and existence of the metallic Pd phase from PXRD pattern (Supplementary Fig. 8), in agreement with the bridge and hollow-CO peaks of DRIFTS. The chemical states of $\mathrm{Pd}$ in 

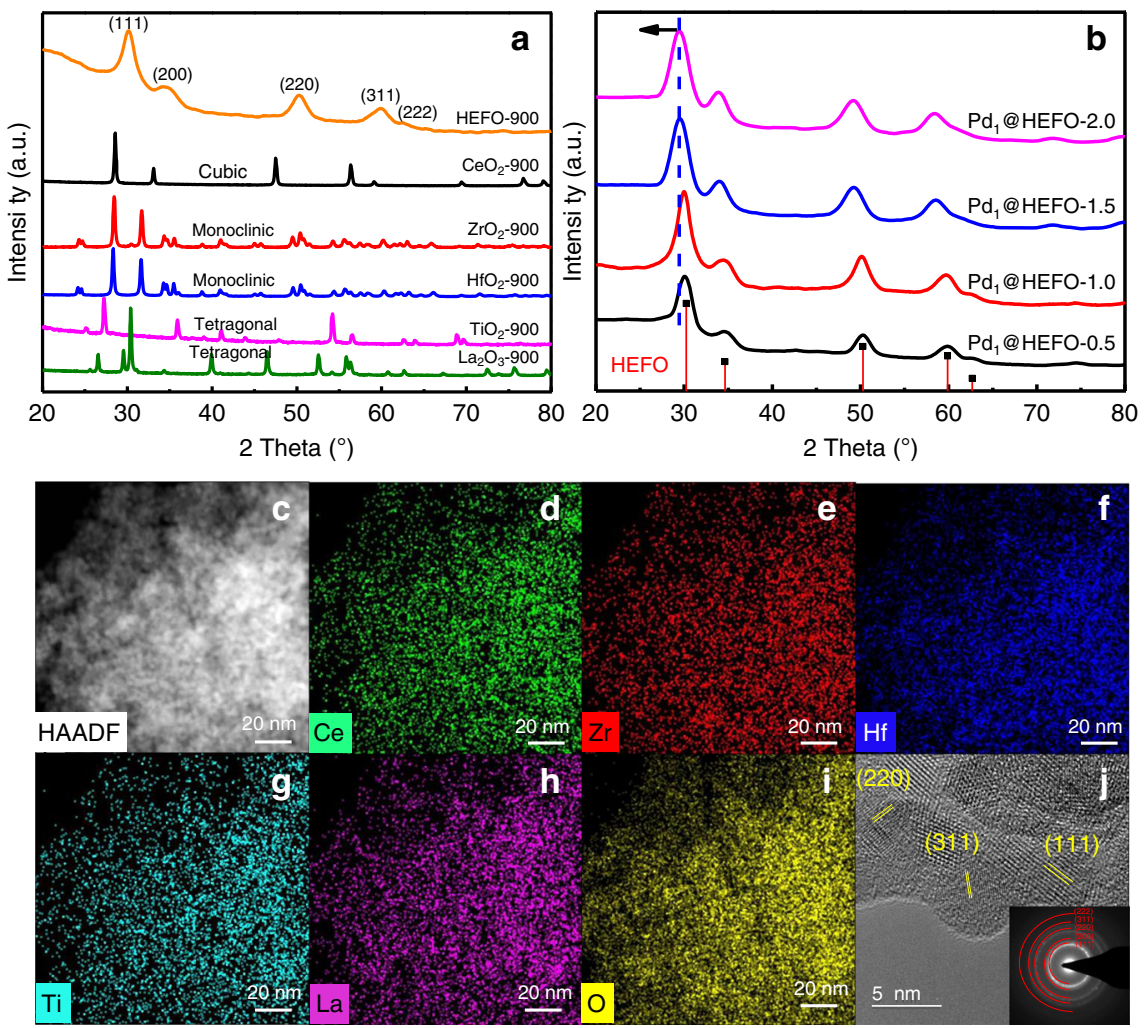

k

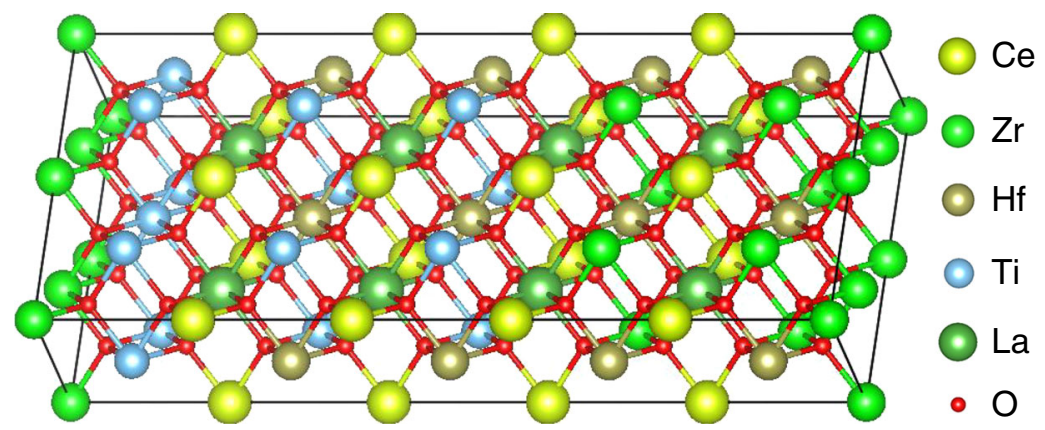

Fig. 2 Structural characterizations of $\mathbf{H E F O}$ and $\mathbf{P d}$ @ $\mathbf{H E F O}$ catalyst. a PXRD patterns of $\mathrm{HEFO}, \mathrm{CeO}_{2}, \mathrm{ZrO}_{2}, \mathrm{HfO}_{2}, \mathrm{TiO}_{2}$, and $\mathrm{La}_{2} \mathrm{O}_{3}$ pyrolyzed at $900{ }^{\circ} \mathrm{C}$. b PXRD patterns of $\mathrm{Pd}_{1} @ \mathrm{HEFO}-x$ samples ( $x$ is the Pd weight loading). c EDS mapping of $\mathbf{d} \mathrm{Ce}, \mathbf{e ~ Z r}, \mathbf{f} \mathrm{Hf}, \mathbf{g} \mathrm{Ti}, \mathbf{h} \mathrm{La}$, and $\mathbf{i} \mathrm{O}$ for HEFO. $\mathbf{j} \mathrm{HRTEM}$ image and corresponding FFT pattern (inset) of HEFO. k Schematic model of HEFO. Source data are provided as a Source data file.

$\mathrm{Pd} @ \mathrm{CeO}_{2}$ and $\mathrm{Pd}_{1} @ \mathrm{HEFO}$ are both dominated by $\mathrm{Pd}^{4+}$ based on XPS results (Supplementary Fig. 6), which suggests their similar $\mathrm{Pd}-\mathrm{O}$ coordination number though totally different Pd microenvironment. As is well known, the phase stabilization is a process determined by combination of the enthalpy $(\mathrm{H})$ and entropy (S) effects, which are temperature- and compositiondependent. Compared with the $\mathrm{Pd} @ \mathrm{CeO}_{2}, \mathrm{Pd}_{1} @ \mathrm{HEFO}$ with enhanced compositional complexity provides a higher molar configurational entropy, especially for equimolar cations, which then potentially decreases the Gibbs free energy according to the equation $(\Delta \mathrm{G}=\Delta \mathrm{H}-\mathrm{T} \Delta \mathrm{S})$. This means that the formation of $\left(\mathrm{Pd}_{\mathrm{y}} \mathrm{CeZrHfTiLa}\right) \mathrm{O}_{\mathrm{x}}$ solid solution is an entropy-dominated process, whereas the decreased configuration entropy induces the dissociation of $\left(\mathrm{Pd}_{\mathrm{y}} \mathrm{Ce}\right) \mathrm{O}_{\mathrm{x}}$ as an enthalpy-driven process. To prove this hypothesis, the PXRD patterns of $\mathrm{Pd@Z} \mathrm{Zr}_{2}$, Pd@ $\mathrm{La}_{2} \mathrm{O}_{3}, \mathrm{Pd} @ \mathrm{HfO}_{2}, \mathrm{Pd} @ \mathrm{TiO}_{2}$, ternary Pd@CeZrTiO quaternary $\mathrm{Pd@CeZrHfTiO}$, samples synthesized by the same method are also collected (Supplementary Fig. 8). The diffraction peaks ascribed to metallic $\mathrm{Pd}$ and/or $\mathrm{PdO}$ can be observed, further confirming the importance of the high configurational entropy on stabilizing the Pd single atoms. We also synthesized the Pd/HEFO-p (single Pd atoms dispersed on HEFO carrier) by a post-deposition method, where the single-atom structure can be confirmed by XRD pattern and CO-DRIFTS spectra in Supplementary Fig. 9. Unfortunately, the sintering and aggregation of Pd on HEFO can be obviously observed in Pd/HEFO-p900 after post-treatment at $900{ }^{\circ} \mathrm{C}$, which might be ascribed to the excessive Pd density on HEFO surface.

Catalytic performance. The oxidation of $\mathrm{CO}$, a key reaction in automotive emission abatement, has been extensively investigated in the past decades ${ }^{38-41}$. Therefore, the light-off curves of CO oxidation are measured to evaluate the catalytic efficiency of our as-obtained samples. As depicted in Fig. 5d, HEFO exhibits an inferior catalytic activity of $\mathrm{CO}$ oxidation with a high onset temperature of $230^{\circ} \mathrm{C}$. After doping 1 wt $\%$ Pd, $\mathrm{Pd}_{1} @ H E F O$ shows a dramatically enhanced reactivity with the onset temperature as low as $\sim 80^{\circ} \mathrm{C}$ and complete $\mathrm{CO}$ oxidation at $170^{\circ} \mathrm{C}$. In comparison, the onset temperature and $T_{100}$ over $\mathrm{Pd@CeO}$ are 223 and $253^{\circ} \mathrm{C}$, respectively, much higher than those of $\mathrm{Pd}_{1} @ \mathrm{HEFO}$. It is generally accepted that metal on reducible carrier $\left(\mathrm{CeO}_{2}\right)$ 


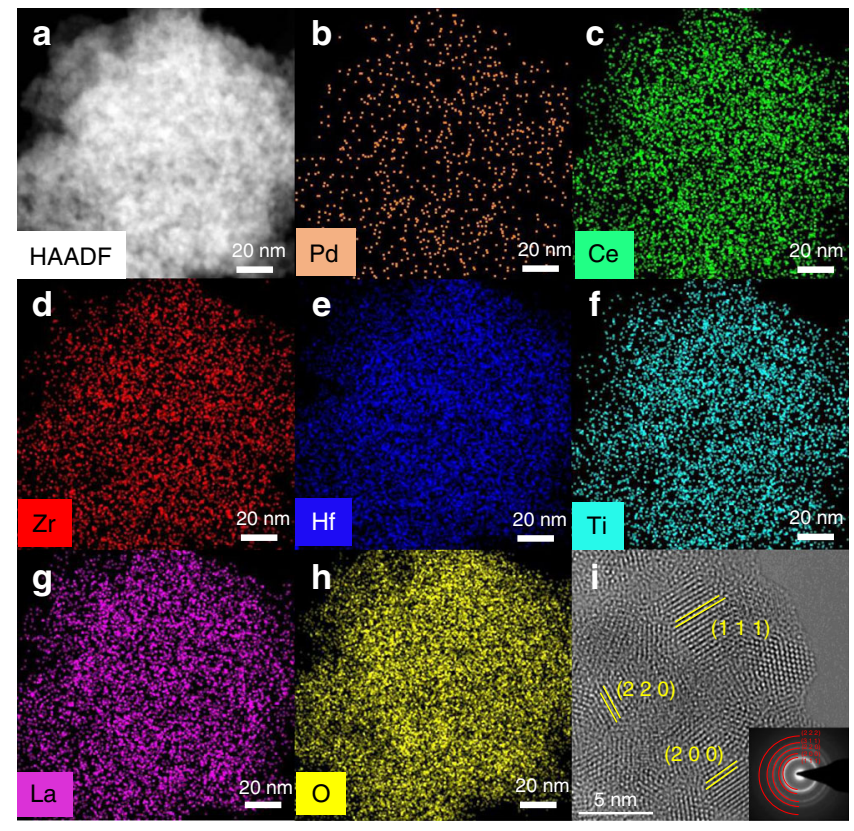

Fig. 3 Microscopic characterizations of Pd $\mathbf{P} @$ HEFO. a EDS-mapping image of $\mathbf{b} \mathrm{Pd}, \mathbf{c} \mathrm{Ce}, \mathbf{d} \mathrm{Zr}$, e Hf, f Ti, $\mathbf{g} \mathrm{La}$, and $\mathbf{h} \mathrm{O}$ for Pd $\mathrm{Pd}_{1} @ \mathrm{HEFO}$; i HRTEM image and corresponding FFT pattern (inset) of $\mathrm{Pd}_{1} @ H E F O$.

follows a Mars-van Krevelen reaction mechanism, where CO adsorbed on metals reacts with active lattice $\mathrm{O}$ from $\mathrm{CeO}_{2}$ to form oxygen vacancies ${ }^{42,43}$. Therefore, the reducibility of the surface lattice $\mathrm{O}$ from the carrier plays an important role in catalytic $\mathrm{CO}$ oxidation. For $\mathrm{Pd} @ \mathrm{CeO}_{2}$, the only reduction peak observed at around $250^{\circ} \mathrm{C}$ is assigned to the reduction of $\mathrm{Pd}-\mathrm{O}-\mathrm{Pd}\left(\mathrm{PdO}_{\mathrm{x}}\right)$ and the surface lattice oxygen in $\mathrm{CeO}_{2}{ }^{44,45}$. In contrast, the surface lattice $\mathrm{O}$ of $\mathrm{HEFO}$ in the vicinity of $\mathrm{Pd}(\mathrm{Pd}-\mathrm{O}-\mathrm{M})$ is easier to be activated for $\mathrm{Pd}_{1} @ H E F O$ compared with $\mathrm{Pd}-\mathrm{O}-\mathrm{Pd}$ for $\mathrm{Pd} @ \mathrm{CeO}_{2}$, which offers a reduction temperature centered at $160{ }^{\circ} \mathrm{C}$. The enhanced reducibility of the surface lattice $\mathrm{O}$ in $\mathrm{Pd}_{1} @ \mathrm{HEFO}$ should be the main cause for its higher catalytic activity. Moreover, XPS spectra of $\mathrm{O} 1 s$ in Fig. $5 c$ show that the ratio of the surface chemisorbed oxygen $\left(\mathrm{O}_{\beta}, 530.4 \mathrm{eV}\right)$ to the support's lattice oxygen $\left(\mathrm{O}_{\alpha}, 528.8 \mathrm{eV}\right)$ of $\mathrm{Pd}_{1} @ \mathrm{HEFO}$ is about twofold higher than that of $\mathrm{Pd} @ \mathrm{CeO}_{2}$, which might be ascribed to the existence of more under-coordinated metal cations due to the incorporation of $\mathrm{Pd}$ into $\mathrm{HEFO}^{46,47}$, consistent with the surface concentration of $\mathrm{Ce}^{3+}$ in Supplementary Fig. 10. These as-formed under-coordinated sites, namely oxygen vacancies, in $\mathrm{Pd}_{1} @ \mathrm{HEFO}$ would render more habitation for $\mathrm{O}_{2}$ dissociation adsorption $^{41}$. Combined CO-TPR with O 1 s XPS results, the improved reducibility of partial surface lattice oxygen in vicinity of Pd and enhanced oxygen vacancies in $\mathrm{Pd}_{1} @ \mathrm{HEFO}$ should be the main cause for its superior catalytic performance. The apparent activation energies $\left(\mathrm{E}_{\mathrm{a}}\right)$ of $\mathrm{Pd} @ \mathrm{CeO}_{2}$ and $\mathrm{Pd}_{1} @ \mathrm{HEFO}$ were calculated, as shown in Fig. 5e. $\mathrm{Pd}_{1} @ \mathrm{HEFO}$ has an $\mathrm{E}_{\mathrm{a}}$ value of $43.40 \mathrm{~kJ} / \mathrm{mol}$, which is much lower than that of $\mathrm{Pd@CeO}$ $(72.21 \mathrm{~kJ} / \mathrm{mol})$, further identify the advantage of $\mathrm{Pd}_{1} @ \mathrm{HEFO}$ catalyst. As shown in Fig. 5f, the cycled measurement of $\mathrm{CO}$ oxidation over $\mathrm{Pd}_{1} @ \mathrm{HEFO}$ and time-on-stream test at $170{ }^{\circ} \mathrm{C}$ (inset) reveal the outstanding stability of $\mathrm{Pd}_{1} @ H E F O$. Since water vapor is usually present in vehicle exhaust, we thereafter examine the hydrothermal stability of both $\mathrm{Pd} @ \mathrm{CeO}_{2}$ and $\mathrm{Pd}_{1} @ \mathrm{HEFO}$ catalysts by treating them at $750{ }^{\circ} \mathrm{C}$ for $10 \mathrm{~h}$ before the activity test. After hydrothermal treatment, the textural and structural properties of $\mathrm{Pd}_{1} @$ HEFO-HA remain almost unchanged (Supplementary Table 2 and Fig. 5). Correspondingly, all elements are still uniformly dispersed without agglomeration and sintering of Pd species from the EDS-mapping result in Supplementary Fig. 11. More importantly, the absence of the bridge and hollow$\mathrm{CO}$ peaks further validates that single-atom $\mathrm{Pd}$ in $\mathrm{Pd}_{1} @ \mathrm{HEFO}-\mathrm{HA}$ is stable under hydrothermal conditions (Supplementary Fig. 12). Consequently, the complete conversion temperature of $\mathrm{CO}$ barely changes after the hydrothermal treatment in Fig. 5d and even 10 vol\% $\mathrm{H}_{2} \mathrm{O}$ in the feed gas $\left(\mathrm{Pd}_{1} @ H E F O-\mathrm{H}_{2} \mathrm{O}\right.$, Supplementary Fig. 13). The increase of lowtemperature catalytic activity of $\mathrm{Pd}_{1} @ \mathrm{HEFO}-\mathrm{HA}$ and $\mathrm{Pd}_{1} @ \mathrm{HEFO}-\mathrm{H}_{2} \mathrm{O}$ (Supplementary Fig. 13) is probably ascribed to the formation of activated surface chemisorbed oxygen $\left(\mathrm{O}_{\beta}\right)$ on HEFO, reported in the previous study ${ }^{41}$. However, the catalytic activity of $\mathrm{Pd} @ \mathrm{CeO}_{2}-\mathrm{HA}$ obviously decreases compared with its fresh counterpart due to the existence sintering of Pd species, evidenced by the decreased linear- $\mathrm{CO}$ and increased bridge and hollow-CO peaks of Pd@ $\mathrm{CeO}_{2}-\mathrm{HA}$ (Supplementary Fig. 12). In addition, $\mathrm{Pd}_{1} @ \mathrm{HEFO}$ not only exhibits better thermal and hydrothermal stability than $\mathrm{Pd} @ \mathrm{CeO}_{2}$ in this work, but also shows better or comparable performance relative to other reported representative catalysts of $\mathrm{CO}$ oxidation ${ }^{20,41,48,49}$. More importantly, $\mathrm{Pd}_{1} @ \mathrm{HEFO}$ exhibits simultaneously outstanding oxidation activities of $\mathrm{CO}, \mathrm{C}_{3} \mathrm{H}_{6}$, and $\mathrm{NO}$ at a high gas-hourly space velocity (GHSV) of $200,000 \mathrm{~mL} \mathrm{gcat}^{-1} \mathrm{~h}^{-1}$ (Supplementary Fig. 14a), although the $T_{100}$ of $\mathrm{CO}$ oxidation shifts to ca. $260^{\circ} \mathrm{C}$ due to the co-presence of $\mathrm{C}_{3} \mathrm{H}_{6}$ and $\mathrm{NO}$ at a high GHSV. The catalytic performance of $\mathrm{Pd}_{1} @ \mathrm{HEFO}$ is comparable to $\mathrm{Pt}$ / $\mathrm{CeO}_{2}-\mathrm{SiAlO}_{\mathrm{x}}$ regarded as a candidate of diesel oxidation catalyst (DOC) ${ }^{50}$ and $\mathrm{Pt} / \mathrm{CeO}_{2}{ }^{40}$. Moreover, no obvious deactivation of $\mathrm{CO}, \mathrm{C}_{3} \mathrm{H}_{6}$, and $\mathrm{NO}$ oxidation can be observed over $\mathrm{Pd}_{1} @ \mathrm{HEFO}$ even after $10 \mathrm{~h}$ of reaction in Supplementary Fig. 14b, implying that $\mathrm{Pd}_{1} @ \mathrm{HEFO}$ shows a good DOC activity and stability. PXRD patterns of $\mathrm{Pd}_{1} @ H E F O$ treated in $\mathrm{H}_{2}$ at different temperatures (Supplementary Fig. 15) suggest that Pd atoms in $\mathrm{Pd}_{1} @ \mathrm{HEFO}$ are not stable in reductive atmosphere. As a result, our $\mathrm{Pd}_{1} @ \mathrm{HEFO}$ is more suitable for the oxidation reaction under the oxygen-rich conditions, such as catalytic destruction of pollutions emitted from diesel engines. These illustrate that our $\mathrm{Pd}_{1} @ \mathrm{HEFO}$ possesses not only outstanding low-temperature $\mathrm{CO}$ oxidation activity but also excellent resistance to hydrothermal degradation as a candidate of DOC, thus possibly tolerating the harsh conditions during exhaust treatment of diesel engines.

\section{Discussion}

In summary, we have developed a solid-state strategy to synthesize a sintering-resistant $\mathrm{Pd}$ single-atom catalyst stabilized on HEFO ( $\left.\mathrm{Pd}_{1} @ \mathrm{HEFO}\right)$. The as-synthesized single-atom Pd catalyst displays not only superior $\mathrm{CO}$ oxidation activity but also outstanding resistance to thermal and hydrothermal degradation compared with $\mathrm{Pd@CeO} 2$ counterpart prepared using the same method. The choice of host in this work plays a paramount role on the synthesis of single-atom Pd catalysts, which can only be realized with HEFO as the carrier because of its maximum configurational entropy. This trait induces $\mathrm{Pd}$ to be incorporated into the HEFO sublattice during the mechanochemical-assisted preparation process, and the above process cannot be accomplished with $\mathrm{CeO}_{2}$ as an alternative carrier. This work provides a solventfree entropy-driven methodology for the synthesis of SACs and may guide the development of next-generation SACs.

\section{Methods}

Synthesis of HEFO and Pd $\mathbf{P d}_{\mathbf{1}} @$ HEFO. Ce $\left(\mathrm{OOCCH}_{3}\right)_{3}$ (AR, ACROS, USA), $\mathrm{ZrCl}_{4}$ $\left(98 \%+\right.$, Alfa Aesar, USA), $\mathrm{HfCl}_{4}(97.0 \%, \mathrm{ACROS}, \mathrm{USA}), \mathrm{La}\left(\mathrm{NO}_{3}\right)_{3}$ (AR, ACROS, USA), $\mathrm{TiOSO}_{4}\left(99.0 \%\right.$, ACROS, USA), $\mathrm{K}_{2} \mathrm{PdCl}_{6} \cdot \mathrm{xH}_{2} \mathrm{O}$ (99.9\%, ALDRICH, USA), and fumed silica (99.9\%, ALDRICH, USA) equaled to the total weights of the above five metal precursors were massed and added to a commercially available $25 \mathrm{~mL}$ 

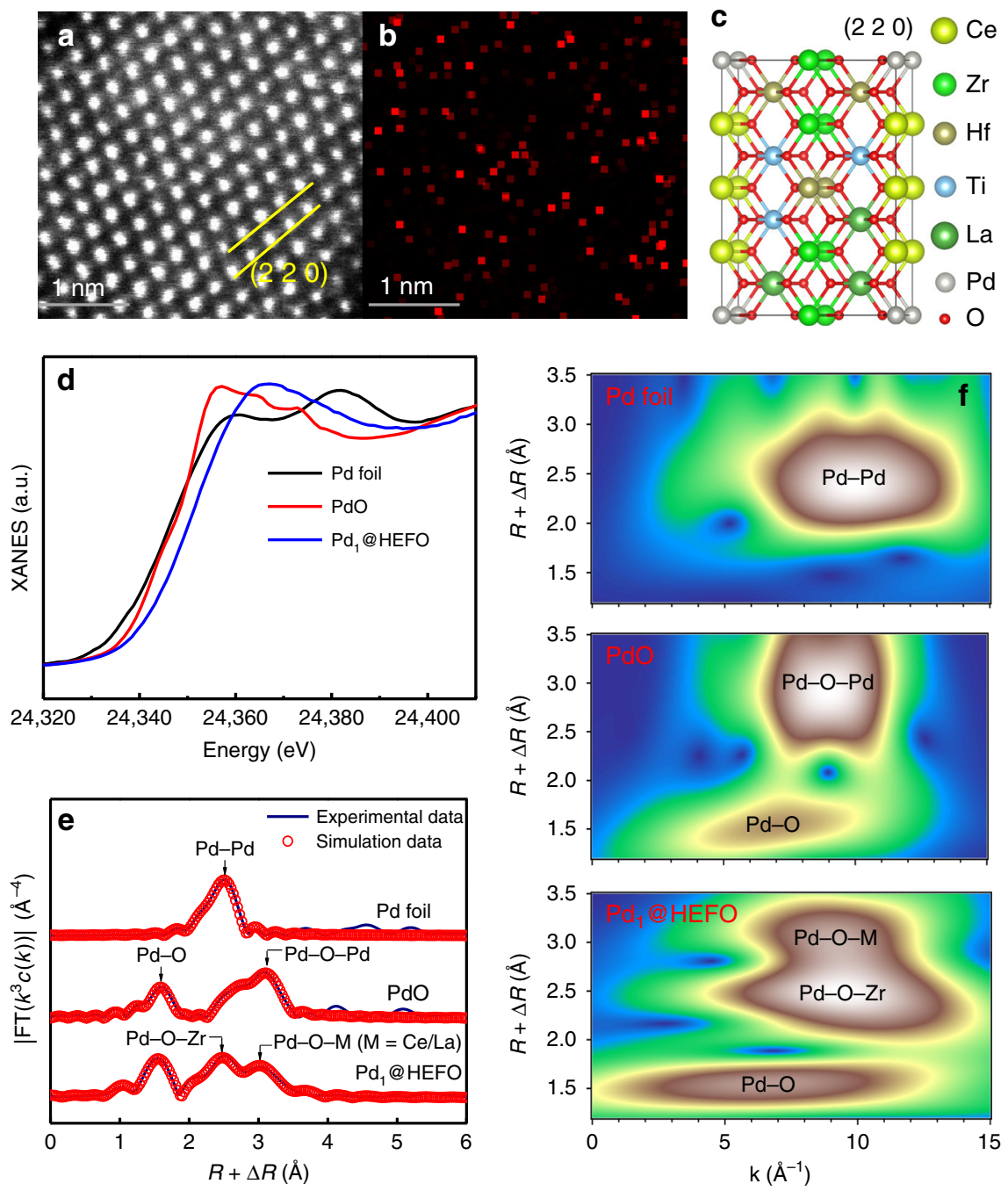

Fig. 4 Electronic properties of Pd $\mathbf{P d}_{\mathbf{1}} @$ HEFO. a HAADF-STEM image of $\mathrm{Pd}_{1} @ H E F O$ and $\mathbf{b}$ corresponding EDS mapping of Pd. c Schematic model of $\mathrm{Pd}_{1} @$ HEFO (220).d XANES spectra at the Pd K-edge. e The $k^{3}$-weighted Fourier transforms of Pd K-edge EXAFS spectra, and $\mathbf{f}$ the wavelet transforms from experimental data for $\mathrm{Pd}_{1} @ \mathrm{HEFO}, \mathrm{PdO}$, and Pd foil. Source data are provided as a Source data file.

screw-capped zirconia vial reactor along with five zirconia balls. The reactor was placed in a high-speed vibrating ball miller (1800 rounds $\mathrm{min}^{-1}, 300 \mathrm{~W}$ motor power) and the mixtures were ball milled twice for 30 min each time. The resulting powder product $\left(\mathrm{Pd} @ \mathrm{CeZrHfTiLaO} \mathrm{x}_{\mathrm{x}} \mathrm{SiO}_{2}\right.$ ) was pyrolyzed at $900^{\circ} \mathrm{C}$ with a heating rate of $2{ }^{\circ} \mathrm{C} \mathrm{min}-1$ for $4 \mathrm{~h}$ under air in a tube furnace and cooled down the room temperature, to obtain the sample named as $\mathrm{Pd}_{1} @ \mathrm{HEFO} @ \mathrm{SiO}_{2}$, and then it was stirred in $2.5 \mathrm{M} \mathrm{NaOH}$ for $8 \mathrm{~h}$ at room temperature and then washed with deionized water, repeating the process four times to remove the silica template, followed by drying at vacuum conditions at $40^{\circ} \mathrm{C}$ overnight, finally achieved the porous $\mathrm{Pd}_{1} @ \mathrm{HEFO}$ samples. Pd $\mathrm{d}_{1} @ \mathrm{HEFO}$ with different Pd loading $(0.5,1.0,1.5$, and $2.0 \mathrm{wt} \% \mathrm{Pd}$ ) were prepared according to the same above steps, denoted as Pd 1 HEFO-0.5, Pd 1 HEFO-1.0, Pd 1 @HEFO-1.5, Pd $@$ @HEFO-2.0, respectively. $\mathrm{Pd}_{1} @$ HEFO-1.0 was chosen to be as the representative sample to investigate the role of HEFO on the formation of the stabled Pd SACs, which was further briefly labeled as $\mathrm{Pd}_{1} @$ HEFO. HEFO sample was prepared by the same steps as $\mathrm{Pd}_{1} @ \mathrm{HEFO}$, without $\mathrm{K}_{2} \mathrm{PdCl}_{6} . \mathrm{Pd} @ \mathrm{CeO}_{2}, \mathrm{Pd} @ \mathrm{ZrO}_{2}, \mathrm{Pd} @ \mathrm{HfO}_{2}, \mathrm{Pd} @ \mathrm{TiO}_{2}$, $\mathrm{Pd} @ \mathrm{La}_{2} \mathrm{O}_{3}, \mathrm{Pd} @ \mathrm{CeZrTiO}$, and $\mathrm{Pd} @ \mathrm{CeZrHfTiO}$ x were also prepared by the same steps as $\mathrm{Pd}_{1} @ \mathrm{HEFO} . \mathrm{Pd}_{1} @ \mathrm{HEFO}$ and $\mathrm{Pd} @ \mathrm{CeO}_{2}$ samples were treated under $10 \mathrm{vol} \%$ water vapor in $\mathrm{N}_{2}$ at $750^{\circ} \mathrm{C}$ for $10 \mathrm{~h}$ and named as $\mathrm{Pd}_{1} @ \mathrm{HEFO}-\mathrm{HA}$ and $\mathrm{Pd} @ \mathrm{CeO}_{2}-\mathrm{HA}$. $\mathrm{Pd}_{1} @ \mathrm{HEFO}$ sample was also treated under 2 vol\% $\mathrm{H}_{2}$ in $\mathrm{He}$ at $250{ }^{\circ} \mathrm{C}$ for $2 \mathrm{~h}$ and named as $\mathrm{Pd}_{1} @ \mathrm{HEFO}-\mathrm{H}_{2}$.

Synthesis of Pd/HEFO-p. The post-deposition of Pd atoms onto HEFO was obtained by the following typical steps: $0.5 \mathrm{~g}$ the pre-synthesized HEFO powder was dispersed in deionized water with rigorous stirring. An appropriate amount of $\mathrm{H}_{2} \mathrm{PdCl}_{6}\left(\mathrm{~K}_{2} \mathrm{PdCl}_{6}\right.$ dissolved in diluted hydrochloric acid, corresponding to a $\mathrm{Pd}$ loading of $0.5 \mathrm{wt} \%$ ) solution was added dropwise into the HEFO solution under magnetically stirring ${ }^{51}$. After continuing stirring for $5 \mathrm{~h}$ and followed by aging for $5 \mathrm{~h}$, the suspension was filtered and washed with deionized water for several times, and dried at $60^{\circ} \mathrm{C}$ under vacuum ${ }^{52}$ and then calcined at 300 and $900{ }^{\circ} \mathrm{C}$ in air for $2 \mathrm{~h}$, respectively, denoted as Pd/HEFO-p and Pd/HEFO-p-900.

Characterizations. X-ray diffraction (XRD) data were recorded on a PANalytical Empyrean diffractometer with a $\mathrm{Cu}-\mathrm{K} \alpha$ radiation source in the $2 \theta$ range of $20-80^{\circ}$. The nitrogen adsorption and desorption isotherms were measured at $77 \mathrm{~K}$ under a Gemini VII surface-area analyzer. Samples were degassed for $6 \mathrm{~h}$ under $\mathrm{N}_{2}$ at $160^{\circ} \mathrm{C}$ prior to the measurement. High-resolution transmission electron microscopy (HRTEM), high-angle annular dark-field scanning transmission electron microscopy (HAADF-STEM) and the corresponding energy-dispersive X-ray spectroscopy (EDS) were conducted on an aberration-corrected Titan S 80-300 (FEI) with an accelerating $300 \mathrm{kV}$ voltage.

The X-ray absorption spectra (XAS) were collected on the beamline BL01C1 in National Synchrotron Radiation Research Center (NSRRC), with electron energy of $1.5 \mathrm{GeV}$ and a beam current between 100 and $200 \mathrm{~mA}$, and XAS data were collected at treatment temperatures. The radiation was monochromatized by a $\mathrm{Si}$ (111) double-crystal monochromator. XANES and EXAFS data reduction and analysis were processed by Athena software. More details on the fitting process are given in the figure legend or table footnote.

In situ diffuse reflectance infrared Fourier transform spectra (DRIFTS) were collected at $30^{\circ} \mathrm{C}$ with a Thermo Nicolet 6700 spectrometer equipped with a mercury cadmium telluride (MCT) detector accumulated at a resolution of $4 \mathrm{~cm}^{-1}$ in 100 scans. Fifty milligrams of samples were preconditioned in situ at $400^{\circ} \mathrm{C}$ under $\mathrm{He}(99.999 \%)$ for $30 \mathrm{~min}$ and then cooled to $250^{\circ} \mathrm{C}$ to be reduced for $30 \mathrm{~min}$ in $5 \mathrm{vol} \% \mathrm{H}_{2} / \mathrm{N}_{2}\left(30 \mathrm{~mL} \mathrm{~min}^{-1}\right)$. Finally, the sample was cooled to $30^{\circ} \mathrm{C}$ prior to recording the background spectra and exposed to $1 \mathrm{vol} \% \mathrm{CO} / \mathrm{N}_{2}$ flow until no change of the spectrum, and the $\mathrm{CO}$ adsorption spectrum was collected after purging in $\mathrm{He}$. 

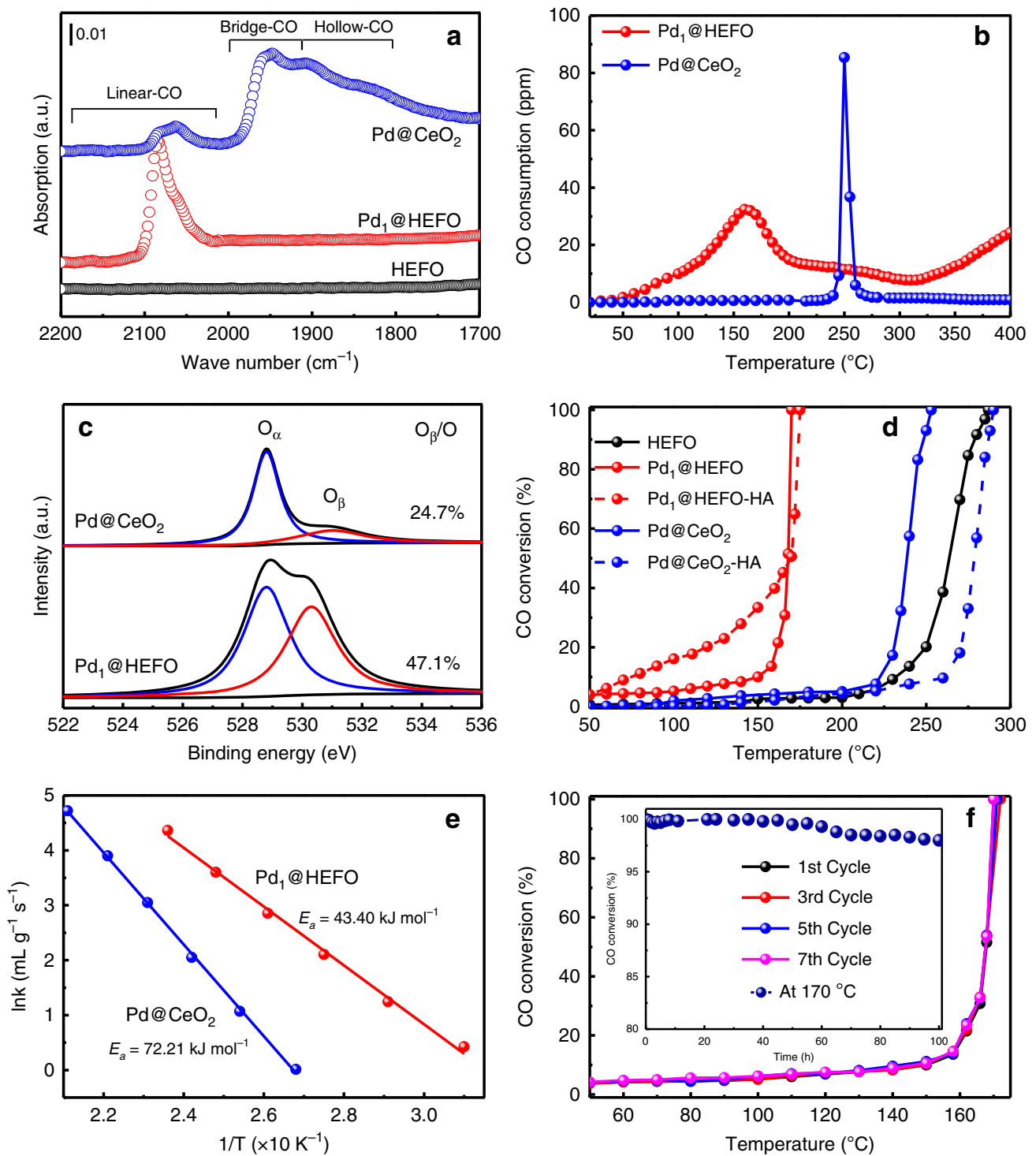

Fig. 5 Catalytic performances of CO oxidation for Pd $\mathbf{P d}_{\mathbf{1}} @ \mathbf{H E F O}$ and $\mathbf{P d} @ \mathbf{C e O}_{\mathbf{2}}$. a CO-DRIFTS results of HEFO, Pd $@$ HEFO, and Pd@CeO 2 . b CO-TPR of Pd1@HEFO and Pd@CeO $\mathrm{C}_{2}$.c XPS profiles of O 1s for Pd $@$ HEFO and Pd@CeO $2 . \mathbf{d}$ CO oxidation of catalytic performance of different catalysts before (solid lines) and after (dashed lines) hydrothermal treatments. Reaction conditions: A catalyst loading of $20 \mathrm{mg}$, and 1 vol\% CO balance in air at a gas-hourly space velocity of 40,000 mL gcat ${ }^{-1} \mathrm{~h}^{-1}$. e Arrhenius plots of $\mathrm{Pd}_{1} @ \mathrm{HEFO}$ and $\mathrm{Pd} @ \mathrm{CeO}_{2}$. f the cycled measurement of CO oxidation over Pd $@ H E F O$ and its stability at $170^{\circ} \mathrm{C}$ (inset). Source data are provided as a Source data file.

X-ray photoelectron spectroscopy (XPS) measurements were performed with a Kratos XSAM-800 Ka instrument. Peak fitting was performed using CasaXPS software (v 2.3.18). The C $1 s$ peak $(284.6 \mathrm{eV})$ was used for the calibration.

The pulse CO chemisorption was measured by Micromeritics AutoChem II 2920. Hundred milligrams of sample was reduced in $\mathrm{H}_{2}$ at $400{ }^{\circ} \mathrm{C}$ for $1 \mathrm{~h}$ and then the sample was cleaned by He for $1 \mathrm{~h}$ with a flow rate of $30 \mathrm{ml} \mathrm{min}^{-1}$. Then, the $\mathrm{CO}$ was injected $(11.10 \mu \mathrm{mol} / \mathrm{pluse})$ into the catalyst in a flow of $\mathrm{He}$ until the amount of $\mathrm{CO}$ uptake was saturated. The exposed Pd atoms were evaluated from the amount of $\mathrm{CO}$ consumption assuming 1 molecule of $\mathrm{CO}$ adsorbed per surface $\mathrm{Pd}$ atom $^{32}$.

CO temperature-programmed reduction (CO-TPR) experiments were conducted by the FTIR spectrometer (Antaris IGS, Nicolet). The powder catalyst put in flow reactor device. Fifty milligrams of sample was put in a fixed bed quartz and pretreated at $450^{\circ} \mathrm{C}\left(10^{\circ} \mathrm{C} \mathrm{min}^{-1}\right)$ in $\mathrm{He}$ for $1 \mathrm{~h}$ and then cooled down to room temperature. Then the sample was heated to $500^{\circ} \mathrm{C}\left(5^{\circ} \mathrm{C} \mathrm{min}-1\right)$ under an atmosphere of $1 \mathrm{vol} \% \mathrm{CO}$ in $\mathrm{He}\left(200 \mathrm{~mL} \mathrm{~min}^{-1}\right)$.

$\mathrm{O}_{2}$-temperature-programmed desorption $\left(\mathrm{O}_{2}\right.$-TPD) experiments were performed on a PX200 apparatus equipped with a TCD. Fifty milligrams of the sample was pretreated in a flow of $\mathrm{N}_{2}\left(20 \mathrm{~mL} \mathrm{~min}^{-1}\right)$ at $400^{\circ} \mathrm{C}$ for $30 \mathrm{~min}$ and then cooled to $80^{\circ} \mathrm{C}$. The adsorption was carried out by $5 \mathrm{vol} \% \mathrm{O}_{2}-95 \mathrm{vol} \% \mathrm{~N}_{2}(30$ $\mathrm{mL} \mathrm{min}{ }^{-1}$ ) at $80^{\circ} \mathrm{C}$ for $30 \mathrm{~min}$. Then the samples were swept at $80^{\circ} \mathrm{C}$ for
$60 \mathrm{~min}$ by $\mathrm{He}$. The desorption was detected from 80 to $400^{\circ} \mathrm{C}$ with a heating rate of $5^{\circ} \mathrm{C} \min ^{-1}$

CO oxidation activity measurement. $\mathrm{CO}$ oxidation reaction was performed in the same manner as our previous work ${ }^{5}$. The outlet concentrations of $\mathrm{CO}$ and $\mathrm{CO}_{2}$ were analyzed using an on-line gas chromatograph (Buck Scientific 910) equipped with a dual molecular sieve/porous polymer column (Alltech CTR1) with a thermal conductivity detector.

The apparent activation energy was calculated using the Arrhenius law $\left(k=A \exp \left(-E_{\mathrm{a}} / R T\right)\right) . E_{\mathrm{a}}$ was obtained from the slope of the linear plot of $\ln (k)$ versus $1000 / T$ and the value of $k$ was calculated using the following equation:

$$
k=(V \times X) / m
$$

Where, $V$ is the total gas flow $\left(\mathrm{mL} \cdot \mathrm{s}^{-1}\right)$ at temperature $T(\mathrm{~K}), X$ is the CO conversion (\%), and $m$ is the catalyst mass in the reactor (g). In this work, the weights of $\mathrm{Pd}_{1} @ \mathrm{HEFO}$ and $\mathrm{Pd} @ \mathrm{CeO}_{2}$ are both $10 \mathrm{mg}$.

DOC catalytic activity measurement. The DOC catalytic activity evaluation of $\mathrm{Pd}_{1} @$ HEFO was performed according to the previous work ${ }^{49}$. A catalyst loading of $150 \mathrm{mg}$ at a gas-hourly space velocity (GHSV) of $200,000 \mathrm{~mL} \mathrm{gcat}^{-1} \mathrm{~h}^{-1}$ with the 
total gas flow rate of $500 \mathrm{ml} \mathrm{min}^{-1}$ was used. The outlet flows of $\mathrm{CO}, \mathrm{C}_{3} \mathrm{H}_{6}$, NO, and $\mathrm{NO}_{2}$ were analyzed using a Nicolet Antaris IGS-6700 gas analyzer (Thermo Fisher Scientific, USA).

\section{Data availability}

All the data that support the plots within this paper and its Supplementary Information are available from the corresponding author upon reasonable request. Source data are provided with this paper.

Received: 23 January 2020; Accepted: 10 July 2020;

Published online: 06 August 2020

\section{References}

1. Cantor, B., Chang, I. T. H., Knight, P. \& Vincent, A. J. B. Microstructural development in equiatomic multicomponent alloys. Mater. Sci. Eng. A 375, 213-218 (2004).

2. Yeh, J.-W. et al. Nanostructured high-entropy alloys with multiple principal elements: novel alloy design concepts and outcomes. Adv. Eng. Mater. 6, 299-303 (2004).

3. Gludovatz, B. et al. A fracture-resistant high-entropy alloy for cryogenic applications. Science 345, 1153-1158 (2014).

4. Rost, C. M. et al. Entropy-stabilized oxides. Nat. Commun. 6, 8485 (2015).

5. Zhang, Z. et al. Mechanochemical nonhydrolytic sol-gel-strategy for the production of mesoporous multimetallic oxides. Chem. Mater. 31, 5529-5536 (2019).

6. Yi, C. et al. Entropic stabilization of mixed A-cation $\mathrm{ABX}_{3}$ metal halide perovskites for high performance perovskite solar cells. Energy Environ. Sci. 9, 656-120 (2016).

7. Sarkar, A. et al. Rare earth and transition metal based entropy stabilised perovskite type oxides. J. Eur. Ceram. Soc. 38, 2318-2327 (2018).

8. Dąbrowa, J. et al. Synthesis and microstructure of the (Co, Cr, Fe, Mn, Ni) $)_{3} \mathrm{O}_{4}$ high entropy oxide characterized by spinel structure,. Mater. Lett. 216, 32-36 (2018).

9. Djenadic, R. et al. Multicomponent equiatomic rare earth oxides. Mater. Res. Lett. 5, 102-109 (2017).

10. Sarkar, A. et al. Multicomponent equiatomic rare earth oxides with a narrow band gap and associated praseodymium multivalency. Dalton Trans. 46, 12167-12176 (2017).

11. Gild, J. et al. High-entropy fluorite oxides. J. Eur. Ceram. Soc. 38, 3578-3584 (2018).

12. Cen, K. et al. A five-component entropy-stabilized fluorite oxide. J. Eur. Ceram. Soc. 38, 4161-4164 (2018).

13. Mitchell, S., Vorobyeva, E. \& Pérez-Ramírez, J. The multifaceted reactivity of single-atom heterogeneous catalysts. Angew. Chem. Int. Ed. 57, 15316-15329 (2018).

14. Chen, Y. et al. Single-atom catalysts: synthetic strategies and electrochemical applications. Joule 2, 1242-1264 (2018).

15. Yang, X. et al. Single-atom catalysts: a new frontier in heterogeneous catalysis. Acc. Chem. Res. 46, 1740-1749 (2013).

16. Jin, T. et al. Mechanochemical-assisted synthesis of high-entropy metal nitride via a soft urea strategy. Adv. Mater. 30, 1707512-1707516 (2018).

17. He, X. et al. Mechanochemical kilogram-scale synthesis of noble metal singleatom catalysts. Cell Rep. Phys. Sci. 1, 10004 (2020).

18. Liu, K. et al. Strong metal-support interaction promoted scalable production of thermally stable single-atom catalysts. , Nat. Commun. 11, 1263 (2020).

19. Qiao, B. et al. Single-atom catalysis of $\mathrm{CO}$ oxidation using $\mathrm{Pt}_{1} / \mathrm{FeO}_{\mathrm{x}}$. Nat. Chem. 3, 634-641 (2011)

20. Spezzati, G. et al. Atomically dispersed $\mathrm{Pd}-\mathrm{O}$ Species on $\mathrm{CeO}_{2}(111)$ as highly active sites for low-temperature CO oxidation. ACS Catal. 7, 6887-6891 (2017).

21. Qiao, B. et al. Highly efficient catalysis of preferential oxidation of $\mathrm{CO}$ in $\mathrm{H}_{2}$ Rich stream by gold single-atom catalysts. ACS Catal. 5, 6249-6254 (2015).

22. Liu, J. et al. Tackling CO poisoning with single-atom alloy catalysts. J. Am. Chem. Soc. 138, 6396-6399 (2016).

23. Wang, X. et al. Uncoordinated amine groups of metal-organic frameworks to anchor single $\mathrm{Ru}$ sites as chemoselective catalysts toward the hydrogenation of quinoline. J. Am. Chem. Soc. 139, 9419-9422 (2019).

24. Cheng, Y. et al. Atomically dispersed transition metals on carbon nanotubes with ultrahigh loading for selective electrochemical carbon dioxide reduction. Adv. Mater. 30, 1706287-1706293 (2018).

25. Hegde, M. S., Madras, G. \& Patil, K. C. Noble metal ionic catalysts. Acc. Chem. Res. 42, 704-712 (2009).
26. Newton, M. A., Belver-Coldeira, C., Martínez-Arias, A. \& Fernández-García M. Dynamic in situ observation of rapid size and shape change of supported Pd nanoparticles during CO/NO cycling. Nat. Mater. 6, 528-532 (2007).

27. Stonkus, O. A., Kardash, T. Y., Slavinskaya, E. M., Zaikovskii, V. I. \& Boronin, A. I. Thermally induced structural evolution of palladium-ceria catalysts. Implication for CO oxidation. ChemCatChem 11, 3505-3521 (2019).

28. Wang, $\mathrm{H}$. et al. Surpassing the single-atom catalytic activity limit through paired Pt-O-Pt ensemble built from isolated $\mathrm{Pt}_{1}$ atoms. Nat. Commun. 10, 3808 (2019).

29. Yan, H. et al. Single-atom $\mathrm{Pd}_{1} /$ graphene catalyst achieved by atomic layer deposition: remarkable performance in selective hydrogenation of 1,3butadiene. J. Am. Chem. Soc. 137, 10484-10487 (2015).

30. Kobayashi, T., amada, T. \& Kayano, K. Effect of basic metal additives on $\mathrm{NO}_{\mathrm{x}}$ reduction property of $\mathrm{Pd}$-based three-way catalyst. Appl. Catal. B: Environ. 30, 287-292 (2001).

31. Zhou, S. et al. Pd single-atom catalysts on nitrogen-doped graphene for the highly selective photothermal hydrogenation of acetylene to ethylene. Adv. Mater. 31, 1900509-1900515 (2019).

32. Sheu, H.-S., Lee, J.-F., Shyu, S.-G., Chou, W.-W. \& Chang, J.-R. Sulfur resistance enhancement by grafted $\mathrm{TiO}_{2}$ in $\mathrm{SiO}_{2}$-supported $\mathrm{Pd}$ catalysts: role of grafted $\mathrm{TiO}_{2}$ and genesis of Pd clusters. J. Catal. 266, 15-25 (2009).

33. Ankudinov, A. L. Real-space multiple-scattering calculation and interpretation of x-ray-absorption near-edge structure. Phy. Rev. B 58, 7565-7576 (1998).

34. Jeong, H., Bae, J., Han, J. W. \& Lee, H. Promoting effects of hydrothermal treatment on the activity and durability of $\mathrm{Pd} / \mathrm{CeO}_{2}$ catalysts for $\mathrm{CO}$ oxidation. ACS Catal. 7, 7097-7105 (2017).

35. Tiznado, H., Fuentes, S. \& Zaera, F. Infrared study of CO adsorbed on Pd/ $\mathrm{Al}_{2} \mathrm{O}_{3}-\mathrm{ZrO}_{2}$. Effect of zirconia added by impregnation. Langmuir 20, 10490-10497 (2004)

36. Zeinalipour-Yazdi, C. D., Willock, D. J., Thomas, L., Wilson, K. \& Lee, A. F. $\mathrm{CO}$ adsorption over Pd nanoparticles: a general framework for IR simulations on nanoparticles. Surf. Sci. 646, 210-220 (2016).

37. Carter, J. H. et al. Synergy and anti-synergy between palladium and gold in nanoparticles dispersed on a reducible support. ACS Catal. 6, 6623-6633 (2016).

38. Cargnello, M. et al. Control of metal nanocrystal size reveals metal-support interface role for ceria catalysts. Science 341, 771-773 (2013).

39. Dung, K. et al. Identification of active sites in $\mathrm{CO}$ oxidation and water-gas shift over supported Pt catalysts. Science 350, 189-192 (2015).

40. Jones, J. et al. Thermally stable single-atom platinum-on-ceria catalysts via atom trapping. Science 353, 150-154 (2016).

41. Nie, L. et al. Activation of surface lattice oxygen in single-atom $\mathrm{Pt} / \mathrm{CeO}_{2}$ for low-temperature CO oxidation. Science 358, 1419-1423 (2017).

42. Peterson, E. J. et al. Low-temperature carbon monoxide oxidation catalyzed by regenerable atomically dispersed palladium on alumina. Nat. Commun. 5, 4885 (2014).

43. Wang, A., Li, J. \& Zhang, T. Heterogeneous single-atom catalysis. Nat. Rev. Chem. 2, 65-81 (2018).

44. Pereira-Hernández, X. I. et al. Tuning Pt- $\mathrm{CeO}_{2}$ interactions by high temperature vapor-phase synthesis for improved reducibility of lattice oxygen. Nat. Commun. 10, 1358 (2019)

45. Ke, J. et al. Strong local coordination structure effects on subnanometer $\mathrm{PtO}_{\mathrm{x}}$ clusters over $\mathrm{CeO}_{2}$ nanowires probed by low-temperature $\mathrm{CO}$ oxidation. ACS Catal. 5, 5164-5173 (2015).

46. $\mathrm{Xu}, \mathrm{H}$. et al. Design and synthesis of highly-dispersed $\mathrm{WO}_{3}$ catalyst with highly effective $\mathrm{NH}_{3}-\mathrm{SCR}$ activity for $\mathrm{NO}_{\mathrm{x}}$ abatement. ACS Catal. 9, 11557-11562 (2019)

47. Tan, H., Wang, J., Yu, S. \& Zhou, K. Support morphology-dependent catalytic activity of $\mathrm{Pd} / \mathrm{CeO}_{2}$ for formaldehyde oxidation. Environ. Sci. Technol. 49, 8675-8682 (2015)

48. Bai, Y., Wang, C., Zhou, X., Lu, J. \& Xiong, Y. Atomic layer deposition on Pd nanocrystals for forming $\mathrm{Pd}-\mathrm{TiO}_{2}$ interface toward enhanced $\mathrm{CO}$ oxidation. Prog. Nat. Sci. 26, 289-294 (2016)

49. Slavinskaya, E. M. et al. Low-temperature $\mathrm{CO}$ oxidation by $\mathrm{Pd} / \mathrm{CeO}_{2}$ catalysts synthesized using the coprecipitation method. Appl. Catal. B: Environ. 166167, 91-103 (2015)

50. Ding, X. et al. New insights into excellent catalytic performance of the Cemodified catalyst for CO oxidation. Ind. Eng. Chem. Res. 58, 7876-7885 (2019).

51. Zhou, H. et al. Recover the activity of sintered supported catalysts by nitrogendoped carbon atomization. Nat. Commun. 11, 335 (2020).

52. Ren, Y. et al. Unraveling the coordination structure-performance relationship in $\mathrm{Pt}_{1} / \mathrm{Fe}_{2} \mathrm{O}_{3}$ single-atom catalyst. Nat. Commun. 10, 4500 (2019).

\section{Acknowledgements}

Z.Z., J.L., C.D., H.C., and S.D. were supported by the U.S. Department of Energy, Office of Science, Office of Basic Energy Sciences, Chemical Sciences, Geosciences, and Biosciences 
Division, Catalysis Science program. H.X., S.X., Q.L., Y.J., and Y.W. were supported by the National Natural Science Foundation of China (Nos. 21802099, 21972098), National Key Research \& Development Program of China (No. 2016YFC0204901), National Engineering Laboratory for Mobile Source Emission Control Technology (No. NELMS2017A06) and Sichuan Science and Technology Program (No. 2018GZ0401). Y.C. and J.W. were supported by the National Natural Science Foundation of China (No. 21673146). H.X. also thanks the China Scholarship Council for financial support as a visiting scholar. Authors thank Dr. Miaomiao Liu in East China University of Science and Technology for giving the comments on the Scheme and Ms. Jia Li in Sichuan University for the models of HEFO and $\mathrm{Pd}_{1} @$ HEFO. Ceshigo Research Service for agency STEM and XAS, www.ceshigo.com.

\section{Author contributions}

S.D. conceived the research idea and H.X., Y.W., and Y.C. designed the experiments. H.X. performed all the experiments and analyzed all the data. Z.Z. analyzed the data of TEM, XAS, and CO-DRIFTS. J.L. and H.C. carried out XRD and XPS tests. C.D. took part in the synthesis of samples. S.X. and Q.L. carried out the CO-TPR and $\mathrm{O}_{2}$-TPD tests. Y.J. and J.W. discussed the results and commented on the paper. H.X., Z.Z., C.D., Y.W., Y.C., and S.D. co-wrote and revised the paper.

\section{Competing interests}

The authors declare no competing interests.

\section{Additional information}

Supplementary information is available for this paper at https://doi.org/10.1038/s41467020-17738-9
Correspondence and requests for materials should be addressed to Y.W., Y.C. or S.D.

Peer review information Nature Communications thanks the anonymous reviewer(s) for their contribution to the peer review of this work. Peer reviewer reports are available.

Reprints and permission information is available at http://www.nature.com/reprints

Publisher's note Springer Nature remains neutral with regard to jurisdictional claims in published maps and institutional affiliations.

\section{(c) (i)}

Open Access This article is licensed under a Creative Commons Attribution 4.0 International License, which permits use, sharing, adaptation, distribution and reproduction in any medium or format, as long as you give appropriate credit to the original author(s) and the source, provide a link to the Creative Commons license, and indicate if changes were made. The images or other third party material in this article are included in the article's Creative Commons license, unless indicated otherwise in a credit line to the material. If material is not included in the article's Creative Commons license and your intended use is not permitted by statutory regulation or exceeds the permitted use, you will need to obtain permission directly from the copyright holder. To view a copy of this license, visit http://creativecommons.org/ licenses/by/4.0/.

This is a U.S. government work and not under copyright protection in the U.S.; foreign copyright protection may apply 2020 